\title{
The Role of Extracellular Histones in Influenza Virus Pathogenesis
}

\author{
Harshini K. Ashar, ${ }^{*}$ Nathan C. Mueller, ${ }^{*}$ Jennifer M. Rudd, ${ }^{*}$ Timothy A. Snider, ${ }^{*}$ Mallika Achanta, ${ }^{*}$ Maram Prasanthi, * \\ Sivasami Pulavendran, ${ }^{*}$ Paul G. Thomas, ${ }^{\dagger}$ Akhilesh Ramachandran, ${ }^{*}$ Jerry R. Malayer, ${ }^{*}$ Jerry W. Ritchey, ${ }^{*}$ \\ Rachakatla Rajasekhar, Vincent T.K. Chow, ${ }^{\ddagger}$ Charles T. Esmon, ${ }^{\ddagger}$ and Narasaraju Teluguakula*
}

\begin{abstract}
From the Center for Veterinary Health Sciences, * Oklahoma State University, Stillwater, Oklahoma; the Department of Immunology, ${ }^{\dagger}$ St. Jude Children's Research Hospital, Memphis, Tennessee; the Department of Anatomy, ${ }^{\ddagger}$ Arkansas College of Osteopathic Medicine, Fort Smith, Arkansas; the Department of Microbiology and Immunology, ${ }^{\S}$ School of Medicine, National University of Singapore, National University Health System, Singapore; and the Coagulation Biology Laboratory, "Oklahoma Medical Research Foundation, and Department of Pathology, Department of Biochemistry \& Molecular Biology, University of Oklahoma Health Sciences Center, Oklahoma City, Oklahoma
\end{abstract}

\author{
Accepted for publication \\ September 21, 2017. \\ Address correspondence to \\ Narasaraju Teluguakula, Ph.D., \\ Oklahoma State University, 264 \\ McElroy Hall, Stillwater, OK \\ 74078. E-mail: narasa@ \\ okstate.edu.
}

\begin{abstract}
Although exaggerated host immune responses have been implicated in influenza-induced lung pathogenesis, the etiologic factors that contribute to these events are not completely understood. We previously demonstrated that neutrophil extracellular traps exacerbate pulmonary injury during influenza pneumonia. Histones are the major protein components of neutrophil extracellular traps and are known to have cytotoxic effects. Here, we examined the role of extracellular histones in lung pathogenesis during influenza. Mice infected with influenza virus displayed high accumulation of extracellular histones, with widespread pulmonary microvascular thrombosis. Occluded pulmonary blood vessels with vascular thrombi often exhibited endothelial necrosis surrounded by hemorrhagic effusions and pulmonary edema. Histones released during influenza induced cytotoxicity and showed strong binding to platelets within thrombi in infected mouse lungs. Nasal wash samples from influenza-infected patients also showed increased accumulation of extracellular histones, suggesting a possible clinical relevance of elevated histones in pulmonary injury. Although histones inhibited influenza growth in vitro, in vivo treatment with histones did not yield antiviral effects and instead exacerbated lung pathology. Blocking with antihistone antibodies caused a marked decrease in lung pathology in lethal influenza-challenged mice and improved protection when administered in combination with the antiviral agent oseltamivir. These findings support the pathogenic effects of extracellular histones in that pulmonary injury during influenza was exacerbated. Targeting histones provides a novel therapeutic approach to influenza pneumonia. (Am J Pathol 2018, 188: 135-148; https://doi.org/10.1016/j.ajpath.2017.09.014)
\end{abstract}

Influenza pneumonia, caused by highly pathogenic influenza viral infection, has remained a top global health concern for more than a century. The majority of patients who succumb to severe influenza pneumonia develop complications of acute respiratory distress syndrome (ARDS), which is characterized by alveolar capillary damage, edema, parenchymal hemorrhage, pulmonary microvascular thrombosis (MT), and hyperinflammatory cytokine responses. ${ }^{1-5}$ The pathologic and clinical manifestations of ARDS are well characterized in animal models of influenza. ${ }^{6-8}$ In addition to virus-inflicted damage, host-mediated factors are linked to lung pathology and respiratory failure ${ }^{9-11}$ in severe influenza pneumonia.
Our previous studies have demonstrated that excessive neutrophils and neutrophil extracellular traps (NETs) contribute to acute lung damage in influenza infection, as well as during Streptococcus pneumoniae superinfection after influenza infection, in mice. ${ }^{7,12-16}$ Chromatin strands in the NETs disrupt

\footnotetext{
Supported by National Institute of General Medical Sciences NIH award P20GM103648; an Oklahoma Center for the Advancement of Science \& Technology grant; a Center for Veterinary Health Sciences, Oklahoma State University grant (N.T.); and National Heart, Lung \& Blood Institute NIH grant UM1 HL120877 (C.T.E.).

Disclosures: None declared.
} 
the alveolar-capillary barrier, resulting in epithelial injury, vascular leakage, and hemorrhage. ${ }^{7}$ Although the bactericidal effects of NETs have been well characterized, influenza-induced NETs lack bactericidal effects. ${ }^{7}{ }^{12}$ Histones are the major protein components of NETs and are essential components in chromatin organization in the intact cell. However, accumulating evidence indicates that histone proteins released from NETs or dying cells contribute to tissue injury and death in several clinical conditions, including trauma, sepsis, aggravated kidney injury, and acid aspiration-induced ARDS. ${ }^{17-22}$ Histone proteins interact with membrane phospholipids and enhance intracellular calcium influx, which triggers cytotoxic responses. ${ }^{19}$ Histone proteins also promote platelet aggregation by interacting with fibrinogen receptors. ${ }^{23}$

Increased pulmonary capillary thrombosis, platelet activation and aggregation, and endothelial damage have been linked to inflammation and severe lung pneumonia during influenza. ${ }^{24-26}$ Among various inflammatory mediators that contribute to the development of thrombosis, CD40 ligand (L), a tumor necrosis family protein cytokine, is well characterized in its potential role in platelet aggregation and thrombosis. ${ }^{27} \mathrm{CD} 40 \mathrm{~L}$ is abundantly expressed in platelets and other leukocytes. ${ }^{28}$ Soluble (s) CD40L, a cleavage product of $\mathrm{CD} 40 \mathrm{~L}$, is a strong inducer of platelet aggregation and induces B-cell proliferation and isotope switching during immune responses. ${ }^{27,29}$ It has been reported that $95 \%$ of circulating $\mathrm{sCD} 40 \mathrm{~L}$ is secreted from platelets, suggesting that histone-platelet interaction may be crucial in the development of thrombosis. ${ }^{30}$

Due to the difficulty in predicting emerging new influenza strains, the preparation of an effective influenza vaccine is very challenging. Because severe lung pathology in influenza is mediated by virus and host factors, treatment with antiviral drugs does not always effectively control mortality rates. $^{31-33}$ The use of antiviral drugs is also limited by adverse effects on the host and the rapid development of resistance in several strains of influenza. ${ }^{32,33}$ Similarly, we found that targeting a host-mediated factor alone does not protect from lethal influenza challenge. ${ }^{34}$ Targeting both the virus and host factors may be a better choice for influenza treatment. ${ }^{35-37}$ In support of this hypothesis, our previous findings showed that treatment with hepatocyte growth factor, a mitogen for alveolar epithelial cells, together with the antiviral agent oseltamivir, decreases lung pathology in mice challenged with lethal influenza virus. ${ }^{38}$

We hypothesized that extracellular histones released during influenza infection contribute to alveolitis and endothelial damage and trigger MT; these events eventually lead to the pathologic manifestations of ARDS. Here, we examined the role of extracellular histones in influenza virus pathogenesis using an animal model of lethal influenza. We also evaluated the release of extracellular histones in nasal wash and plasma samples collected from influenza-infected patients. Our results show that lethal influenza viral infection promotes the extensive release of extracellular histones into the lung air space. The released extracellular histones induce cytotoxicity and MT, which exacerbate tissue damage. Finally, treatment with antihistone antibodies in combination with oseltamivir ameliorates lung pathology in lethal influenza-challenged mice.

\section{Materials and Methods}

Virus, Animals, and Ethics Approval

Influenza A/Puerto Rico/8/34, H1N1 virus was obtained from ATCC (Manassas, VA). Virus levels were determined by tissue culture infectivity dose $\left(\mathrm{TCID}_{50}\right)$ assay via infection of MadinDarby canine kidney cells. Female BALB/c mice (6 to 8 weeks old) were used in this study. The animals were housed in microisolator cages in a Biosafety Level 2 animal facility. The protocol of the animal experiments was approved by the Institutional Animal Care and Use Committee at Oklahoma State University (protocol number VM-11-43), and the experiments were performed in strict accordance with their recommendations.

\section{Animal Infections}

For infection studies, animals were anesthetized with a mixture of ketamine $(7.5 \mathrm{mg} / \mathrm{kg})$ and xylazine $(0.1 \mathrm{mg} / \mathrm{kg})$ by i.p. injection. The mice were then intranasally challenged with a lethal dose of $2500 \mathrm{TCID}_{50}$ of influenza virus in $50 \mu \mathrm{L}$ phosphate buffered saline. Equal volumes of phosphate-buffered saline were inoculated into control mice.

\section{Histopathology and BAL Analysis}

Mice were anesthetized with ketamine/xylazine by i.p. injection. Tissues for histopathology were collected as described previously. ${ }^{34}$ Lungs from control and infected animals were fixed by the intratracheal instillation of $4 \%$ neutral-buffered formalin at $25 \mathrm{~cm}$ of water gauge pressure and embedded in paraffin. Other major organs, including heart, spleen, intestine, liver, and brain, were also fixed in formalin. Pathologic ARDS lesions were evaluated using a previously described semiquantitative histologic examination scoring method in a blinded manner. ${ }^{39}$ The lung histopathology was scored based on necrotizing bronchiolitis (damage to airway epithelial cells, necrotic bodies, or denudation of airway epithelial lining), inflammation in the bronchioles (bronchioles filled with inflammatory cells, eg, macrophages, neutrophils, and lymphocytes), alveolitis (damaged alveolar epithelial cells or denuded epithelial lining), interstitial inflammation (inflammation in the alveoli or thickening of the alveolar interstitium), hemorrhage (presence of erythrocytes in the alveolar airspace, damaged capillaries, and hemorrhagic effusions in the damaged areas), edema (presence of proteinaceous material in the alveolar airspace), MT (presence of platelet aggregates within the capillaries or occlusions in the small blood vessels of the pulmonary vasculature), and endothelial damage (necrotic endothelium present with in small blood vessels or capillaries). Damage severity was scored on a 5point scale: 0 indicates none or very minor; 1 indicates mild; 2 indicates intermediate; 3 indicates moderately severe; and 4 
indicates severe and widespread. The total lung surface was scored at $400 \times$ magnification, and semiquantitative scores were expressed as means \pm SEM as described previously. ${ }^{7}$ Histopathology scores were represented as mean scores of major lesions, including bronchiolitis, alveolitis, pulmonary edema, hemorrhage, and MT. For bronchoalveolar lavage (BAL) fluid collection, the lungs were washed by two intratracheal administrations of $0.5 \mathrm{~mL}$ of phosphate-buffered saline. ${ }^{7}$ The recovery of BAL fluid was $>90 \%$ in all animals. The BAL fluids were centrifuged at $200 \times g$ for 10 minutes, and the supernatants were stored at $-80^{\circ} \mathrm{C}$. The BAL cells were concentrated using the CytoFuge 2 cytocentrifuge (Stat Spin, Westwood, MA), and differential cell counts were performed using modified Giemsa staining. Protein leakage was measured by the determination of the total BAL protein content using a DC Protein Assay Kit (Bio-Rad, Hercules, CA).

\section{Evaluation of Extracellular Histones in BAL Fluids by Western Blot Analysis}

The BAL fluids were analyzed for the release of extracellular histones and modified histones (citrullinated histones, which are indicative of NET formation), as described previously. ${ }^{7}$ Antibodies against histone proteins $\mathrm{H} 1, \mathrm{H} 2 \mathrm{~A}$, $\mathrm{H} 2 \mathrm{~B}, \mathrm{H} 3, \mathrm{H} 4$, citrullinated H3 (citH3), and citH4 (Millipore, MA) were used. Densitometry analysis was performed on all Western blots for histone proteins using ImageJ software version $1.51(\mathrm{NIH}$, Bethesda, $\mathrm{MD}$; http://imagej.nih.gov/ij).

\section{Flow Cytometry Analysis}

Flow cytometry analysis was performed on platelets collected from mock- or influenza-infected mouse lungs at 3 days postinfection (dpi). Lungs were lavaged with Tyrode buffer pH $7.4(150 \mathrm{mmol} / \mathrm{L}$ sodium chloride, $12 \mathrm{mmol} / \mathrm{L}$ sodium bicarbonate, $0.34 \mathrm{mmol} / \mathrm{L}$ sodium phosphate monobasic, 1 $\mathrm{mmol} / \mathrm{L}$ magnesium chloride, $5 \mathrm{mmol} / \mathrm{L}$ HEPES, $5 \mathrm{mmol} / \mathrm{L}$ glucose, and $1 \%$ bovine serum albumin) containing $1 \%$ formaldehyde. Formalin was added to prevent any activation of platelets during isolation and staining. Leukocytes were removed by centrifuging BAL at $80 \times g$ for 10 minutes. Cellfree BAL supernatants were further centrifuged at $400 \times g$ for 10 minutes to recover platelet pellets. Platelets were then resuspended in Tyrode buffer and stained with antibodies including anti-CD40 PerCP-Cy5.5 or anti-CD41 phycoerythrin (eBioscience, San Diego, CA) or anti-CD40L fluorescein isothiocyanate or anti-CD62p (P-selectin) APC (BioLegend, San Diego, CA). Flow cytometry analysis was performed using a BD FACSCalibur flow cytometer (BD Biosciences, San Jose, CA).

\section{IHC Analysis}

Immunohistochemistry analysis was performed for the detection of NET release using anti-citH3 + antimyeloperoxidase (MPO) or anti-citH4 + anti-MPO antibodies. Anti-citH3 + anti-P-selectin, anti-fibrin + anti-P-selectin, or anti-citH3 + anti-sCD40L were used for the detection of MT as described previously. ${ }^{7}$

\section{Measurement of Extracellular Histones by ELISA}

Extracellular histones released into the cell-free BAL were measured by a cell death enzyme-linked immunosorbent assay (ELISA) kit (Roche, Pleasanton, CA) according to the manufacturer's instructions.

\section{Cytotoxicity Assay}

To determine whether extracellular histones released during influenza infection were functionally active and produced cytotoxic effects, we performed a lactate dehydrogenase release assay using a cytotoxicity detection kit (Roche). The cell-free BAL fluids collected from the control and influenza-infected mice were incubated with alveolar epithelial cells (A549) in the presence or absence of antihistone antibodies $(10 \mu \mathrm{g} / \mathrm{mL}$; antihistones H1, H2A, H2B, H3, H4, citH3, and citH4). About $1.5 \times 10^{4} \mathrm{TCID}_{50} / \mathrm{mL}$ virus levels in BAL fluids were found in influenza-infected mice at 3 dpi. To exclude any cytotoxic effects of the virus, antiserum raised against the influenza virus $(100 \mu \mathrm{g} / \mathrm{mL})$ was also added. To assess the toxic effects of individual histones, recombinant human histones H1, H2A, H2B, H3, H4 (Cayman Chemical Company, Ann Arbor, MI) or total histones (from calf thymus) $5 \mu \mathrm{g} / \mathrm{mL}$ were added to A549 cells or endothelial cells (EA.hy926), and the lactate dehydrogenase release assay was performed.

\section{Analysis of Extracellular Histones in Human Nasal Wash and Plasma Samples}

\section{Study Participants}

Human nasal wash and plasma samples were a gift from Dr. Paul Thomas, St. Jude Children's Research Hospital (Memphis, TN). The inclusion criteria required that participants meet the clinical case definition of influenza virus infection at the time of enrollment as described by Oshansky et al. ${ }^{40}$ The clinical criteria for the inclusion of subjects with influenza included fever or feverishness accompanied by cough or sore throat for 96 hours or less. Children and adults with suspected influenza viral infections receiving medical counsel were approached by study personnel to participate. Index cases, defined as those individuals who tested positive for influenza $\mathrm{A} / \mathrm{B}$ infection, and their respective household contacts were enrolled in the study. The race/ethnicity classifications described in the study were self-reported. Influenza virus A or B diagnosis was confirmed by detection of the matrix gene (influenza A) or nonstructural 1 gene (influenza B) by quantitative real-time RT-PCR. The study was conducted in compliance with Code of Federal Regulations Title 45, Public Welfare Department of Health and Human Services Part 46 and the Declaration of Helsinki. The IRBs of St. Jude Children's Research Hospital and the 
University of Tennessee Health Science Center/Le Bonheur Children's Hospital approved the study protocol. Written informed consent was obtained from the participants' parents/guardians and written assent was obtained from ageappropriate subjects at the time of enrollment. Index cases were asked to provide nasal swabs, nasal lavages, and blood on the day of enrollment (day 0) and days 3, 7, 10, and 28, whereas household contacts were asked to provide nasal swabs on days $0,3,7$, and 14 and blood and nasal lavages on days 0 and 28. Participants were asked to rank their symptom severity daily according to a visual analog scale. In the present study, we included day 0 nasal wash and plasma samples from influenza $\mathrm{A}$-positive, influenza B-positive and -negative samples for the evaluation of extracellular histones.

\section{Measurement of Extracellular Histones in Patients Infected with Influenza}

The release of extracellular histones in nasal wash and plasma samples from influenza A and influenza B viruspositive and influenza-negative patients was analyzed by ELISA.

Measurement of Cytotoxic Effects and MPO Activity in Human Nasal Wash Samples

Cytotoxic effects in nasal wash samples were determined by lactate dehydrogenase release assay as described in Cytotoxicity Assay. MPO activity in the nasal wash samples of influenza-positive and -negative patient samples was determined as described previously, ${ }^{7}$ using the formula: MPO activity (U/mL of nasal wash sample) $=\Delta \mathrm{OD} /$ minute $\times 45.1$, (1) with $1 \mathrm{U}$ of the enzyme defined as the amount that consumes $1 \mu \mathrm{mol}$ of $\mathrm{H}_{2} \mathrm{O}_{2}$ per minute.

\section{Effects of Histone Treatment on Lung Pathology and Virus Loads after Influenza Infection}

A recent study described the antiviral effects of histones in vitro. ${ }^{41}$ To determine whether histones have a protective role in influenza, BALB/c mice were challenged with sublethal $\left(100 \mathrm{TCID}_{50}\right)$ influenza virus. For histone treatment studies, purified histones (50 or $100 \mu \mathrm{g} /$ mouse) were incubated with virus 20 minutes before inoculation into mice, or the histones were administered at 12 hours after influenza infection by intranasal delivery. Histopathology analyses were performed at $3 \mathrm{dpi}$, and virus levels in the lung homogenates were determined using TCID $_{50}$ assay and MadinDarby canine kidney cells.

\section{Histone Toxicity in Vivo}

To determine the effects of extracellular histones released during influenza infection on lung pathogenesis, purified histones (50 or $100 \mu \mathrm{g} / \mathrm{mouse}$ ) were delivered intranasally.
The animals were sacrificed 24 hours after inoculation, and the lungs and other major organs were fixed in formalin for histopathology analysis. Induction of apoptosis by histones was evaluated by terminal deoxynucleotidyl transferase dUTP nick end labeling (TUNEL) assays as described previously. ${ }^{39}$

\section{NETs Induction in Vitro}

To test the effect of released extracellular histones on neutrophils, histones were incubated with neutrophils, collected from mice at 3 dpi. Mouse blood neutrophils were purified using MACS neutrophil isolation kit (Miltenyi Biotec Inc.) by Ly6G antibodies through positive selection. Isolated neutrophils were incubated with purified histones $(2.5,5$, and $10 \mu \mathrm{g} / \mathrm{mL}$ ) in the presence or absence of antihistone antibodies $(10 \mu \mathrm{g} / \mathrm{mL})$. Phorbol 12-myristate 13-acetate (PMA) at a concentration of $20 \mathrm{nmol} / \mathrm{L}$ was used as a positive control for the induction of NETs. NETs released were labeled with Sytox Green staining (Thermo Fisher Scientific, Philadelphia, PA) and visualized using fluorescence microscopy at $400 \times$ magnification. At least five fields on each slide were evaluated to quantify the total positive cells showing NET release. Furthermore, to test whether histones bind to neutrophils, immunostaining was performed for histones using antihistone antibodies on neutrophils isolated from influenza-infected mouse lungs.

\section{Measurement of Soluble CD40L Release in Vivo and in Vitro}

Release of sCD40L during influenza was determined by evaluating SCD40L levels in the control and infected BAL samples by ELISA. To determine whether stimulation with histones induced $\mathrm{sCD} 40 \mathrm{~L}$ release from platelets, mouse platelets were isolated from whole blood. Blood was collected in sodium citrate buffer $(1: 10 \mathrm{v} / \mathrm{v}$ ratio $)$ in the presence of $1 \mu \mathrm{g} /$ $\mathrm{mL}$ prostaglandin $\mathrm{E}_{1}$ to prevent early activation of the platelets. The platelets were isolated by centrifuging the blood at $80 \times g$ for 15 minutes at room temperature. Platelet-rich plasma containing 250,000 cells $/ \mu \mathrm{L}$ was incubated with total histones (100 $\mu \mathrm{g} / \mathrm{mL}$ ) for 20 minutes and then centrifuged at $800 \times g$ for 10 minutes at room temperature. The amount of $\mathrm{SCD} 40 \mathrm{~L}$ released into the supernatant was measured by ELISA. Lipopolysaccharide stimulation was used as a positive control for $\mathrm{SCD} 40 \mathrm{~L}$ release. Plasma fibrinogen degradation product levels were determined by ELISA.

\section{In Vivo Combination Therapy}

For in vivo infection and treatment studies, animals were intranasally challenged with influenza A/Puerto Rico/8/34, $\mathrm{H} 1 \mathrm{~N} 1$ virus $2500 \mathrm{TCID}_{50}$ in $50 \mu \mathrm{L}$ phosphate buffered saline. Monoclonal antihistone antibodies (prepared by C.T.E.) were used. Oseltamivir (20 mg/kg per dose) was administered orally, and antihistone antibody (75 mg/kg per dose) was 

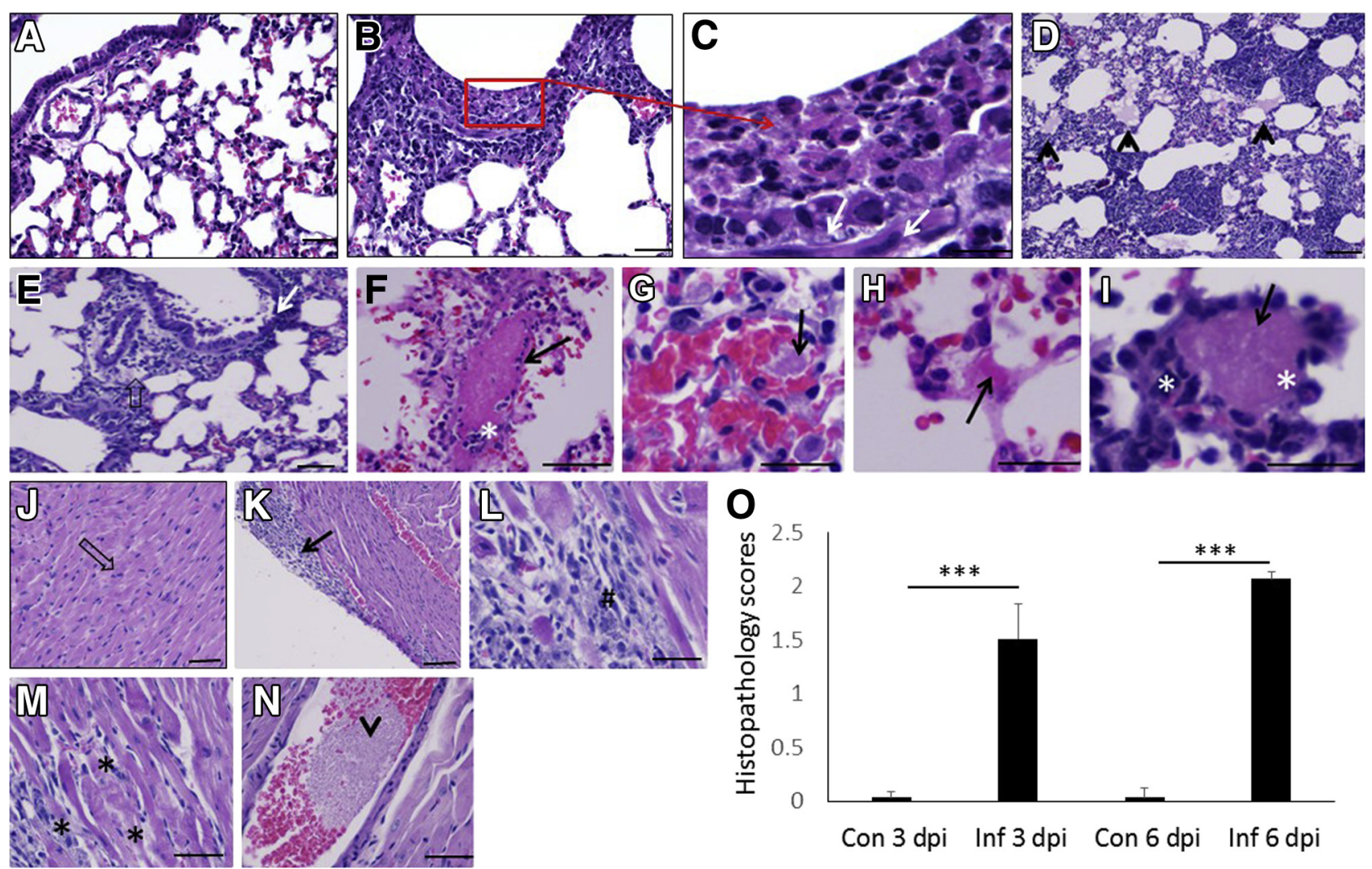

Figure 1 Pathologic acute respiratory distress syndrome lesions in lethal influenza-challenged mice. Paraffin-embedded lung tissues from mice challenged with lethal doses of influenza A/Puerto Rico/8/34 H1N1 virus $\left(2500\right.$ TCID $\left._{50}\right)$ or mock infection were stained with hematoxylin and eosin. A: Lung histopathology from mock-infected mice shows normal lung architecture. B and C: Influenza infection causes severe bronchiolitis and inflammation at 3 days postinfection (dpi; arrows). D and E: At 6 dpi, lungs show severe edema (D, arrowheads), alveolitis, and perivascular expansions with protein exudates (E, open arrow). F-I: Microvascular thrombosis (arrows) is prominently seen in blood vessels at $3 \mathrm{dpi}(\mathbf{F}$ and $\mathbf{H})$ and 6 dpi $(\mathbf{G}$ and $\mathbf{I})$ and is associated with hemorrhage (G) and endothelial necrosis (F and I, asterisks) within the thrombotic lesions. J: The control mice show normal heart on histologic examination (arrow). K-M: Heart histopathology displays mild epicarditis with inflammatory cellular infiltrates (K, arrow; L, hash) and myocarditis with necrotic myocardiocytes and mild inflammation (M, asterisks). N: Thrombotic lesions are also observed in coronary blood vessels (arrowhead). 0: Semiquantitative analysis of histologic examination scores in lung sections from the control (Con) and infected (Inf) groups at 3 and 6 dpi. Data are expressed as means \pm SEM. $n=3$ mice per group (A); $n=4$ mice per group $(\mathbf{B}-\mathbf{N})$. ${ }^{* *} P<0.001$. Scale bars: $40 \mu \mathrm{m}(\mathbf{A}, \mathbf{B}$, and D-N); $20 \mu \mathrm{m}(\mathbf{C})$.

given by s.c. injection. The animals were divided into six groups: i) the noninfected phosphate-buffered saline group (control); ii) the infected group; iii) the group infected with influenza virus and treated with oseltamivir (oseltamivir group); iv) the group infected with influenza virus and treated with antihistone antibody (antihistone antibody group); v) the group infected with influenza virus and treated with oseltamivir and antihistone antibody (dual treatment group); and vi) the noninfected antibody-alone treatment group. The oseltamivir and antihistone antibody treatments were started 48 hours after infection and were given in five doses. To determine the effects of antihistone treatment on lung pathology, the mice were infected and treated as described in the previous section. The lungs were collected at $8 \mathrm{dpi}$ and histopathology analysis was performed. Damage severity was scored on a 5point scale as described previously ${ }^{7}: 0$ indicates none or very minor; 1 indicates mild; 2 indicates intermediate; 3 indicates moderately severe; and 4 indicates severe and widespread,. In another set of experiments, mice were monitored for $>4$ weeks for survival analysis.

\section{Statistical Analysis}

The data are expressed as means \pm SEM. Statistical analyses were performed using a $t$-test or analysis of variance using Prism software version 7 (GraphPad Software, San Diego, CA). $P<0.05$ was considered statistically significant.

\section{Results}

\section{Lethal Influenza Infection in Mice Leads to Severe Lung Damage and Microvascular Thrombosis}

Female BALB/c mice challenged with a lethal dose of influenza virus succumbed to infection by 6 to 8 dpi. Severe lung lesions with extensive pulmonary neutrophil influx, MT, necrotic bronchiolitis, and focal alveolar epithelial disruption were observed at 3 dpi (Figure 1, B and C). Pathologic ARDS lesions were more prominent at $6 \mathrm{dpi}$, with widespread pulmonary edema, vascular leakage, fibrin accumulations in the alveolar airspaces, MT, and diffuse alveolar damage (Figure 1, D and E). 

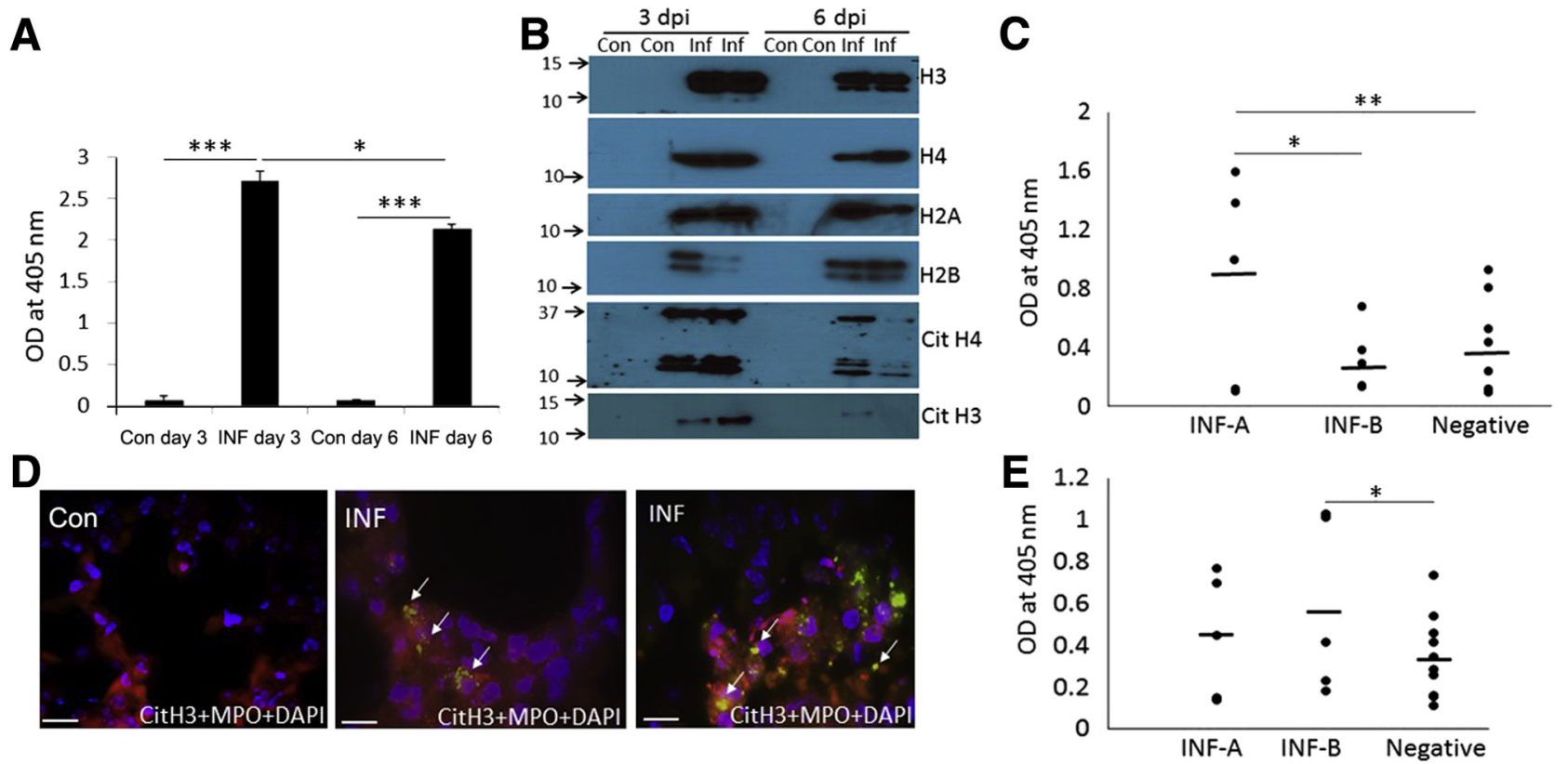

Figure 2 Evidence of the accumulation of extracellular histones in mice and humans infected with influenza virus. A: Evaluation of extracellular histones in bronchoalveolar lavage fluids collected from mock-infected [control (CON)] or influenza-infected (INF) mice at 3 and 6 days postinfection (dpi) by enzymelinked immunosorbent assay (ELISA). Significant histone accumulation is observed at 3 and 6 dpi. B: Detection of BAL histones by Western blot. Histones including $\mathrm{H} 2 \mathrm{~A}, \mathrm{H} 2 \mathrm{~B}, \mathrm{H} 3, \mathrm{H} 4$, citrullinated (cit) $\mathrm{H} 3$, and citH4 are significantly increased at 3 and 6 dpi. C: Total histones in nasal wash samples collected from INF-A, INF-B, and influenza-negative patient samples were evaluated by ELISA. The total level of released histones is significantly higher in INF-A than in INF$B$ and negative samples. D: Double immunostaining of the lungs from the control and infected mice at 3 dpi to detect neutrophil extracellular traps. Tissue sections were stained with citH3 or citH4 (red) and myeloperoxidase (MPO; green). DAPI (blue) was used for DNA staining. Arrows show co-localization of DAPI with histones. Representative images from five individual samples in each group for immunohistochemistry analysis. E: Total histones in plasma samples from INF-A, INF-B, and negative patients were evaluated by ELISA. Total histone levels differ significantly between INF-B patient samples and negative plasma samples. Data are expressed as means \pm SEM. $n=5$ samples per group (D) and INF-A and INF-B (E); $n=10$ negative patient samples and prepared in duplicates (C and D). ${ }^{*} P<0.05,{ }^{*} P<<0.01,{ }^{* * * P}<0.001$. Scale bars $=40 \mu \mathrm{m}$ (D).

Perivascular expansions with protein exudates and infiltrating cells were more obvious at 6 dpi (Figure 1E). Extensive pulmonary MT was observed in the small pulmonary blood vessels and capillaries mainly with platelet aggregates and occasional inflammatory cellular depositions at both 3 dpi (Figure 1, F and $\mathrm{H}$ ) and 6 dpi (Figure 1, G and I). These findings support human autopsy analyses showing widespread hemorrhage, edema, and pulmonary vascular thrombosis in patients who died of severe influenza pneumonia. ${ }^{3,42-44}$ Thrombosis appeared mostly in the nonhilar, peripheral regions of the lungs and blood vessels with complete or partial occlusions by thrombi, which tended to coalesce with regions of hemorrhagic effusion (Figure 1G). Necrotic endothelium was frequently observed in vessels with thrombosis, which may have been a direct result of ischemic necrosis and cellular hypoxia (Figure 1I), and these mice developed severe respiratory distress by 6 dpi. A semiquantitative analysis showed increased lung pathology both at 3 and 6 dpi (Figure 1O). Mock-infected mice did not show any pathologic or clinical lesions at either time interval (Figure 1A).

Histopathologic analysis of the heart revealed mild epicarditis with neutrophil and macrophage infiltrations (Figure 1, K-N). Focal myocardial necrosis was observed in the myocardium, with mild inflammation (Figure 1M). Small thrombotic aggregations in the coronary blood vessels were observed (Figure 1N). The mock-infected mice displayed no pathologic lesions in the heart (Figure 1J). No prominent pathologic changes were observed in other organs, including the brain, liver, spleen, and intestine, after influenza infection.

\section{Influenza Infection Causes High Extracellular Histone Levels in Mouse Lungs}

Our previous findings demonstrated high deposition of NETs in influenza-infected lungs that appeared closely attached to the alveolar epithelium and small blood vessels. ${ }^{7}$ In this study, high histone levels were found in influenza-infected lungs, as evaluated by ELISA, Western blot, and immunohistochemistry analysis. Total histones were significantly increased at both 3 and 6 dpi (Figure 2A) in cell-free BAL supernatants. Individual histones, including $\mathrm{H} 2 \mathrm{~A}, \mathrm{H} 2 \mathrm{~B}, \mathrm{H} 3, \mathrm{H} 4$, and citrullinated histones, including citH3 and citH4 (indicative of NET formation), were detected in BAL supernatants by Western blot analysis (Figure 2B). Densitometry analysis showed significant increases in all histone types (normal and citrullinated histones) after influenza infection at both 3 and 6 dpi compared with those in the mock-infected animal groups (Supplemental Figure S1). NET release was further confirmed by immunostaining analysis with antibodies against citH4 or citH3 together with MPO and DAPI. A strong co-localization of citH4 or citH3 with MPO and DNA was found within the damaged areas of the lungs (Figure 2D). 
A
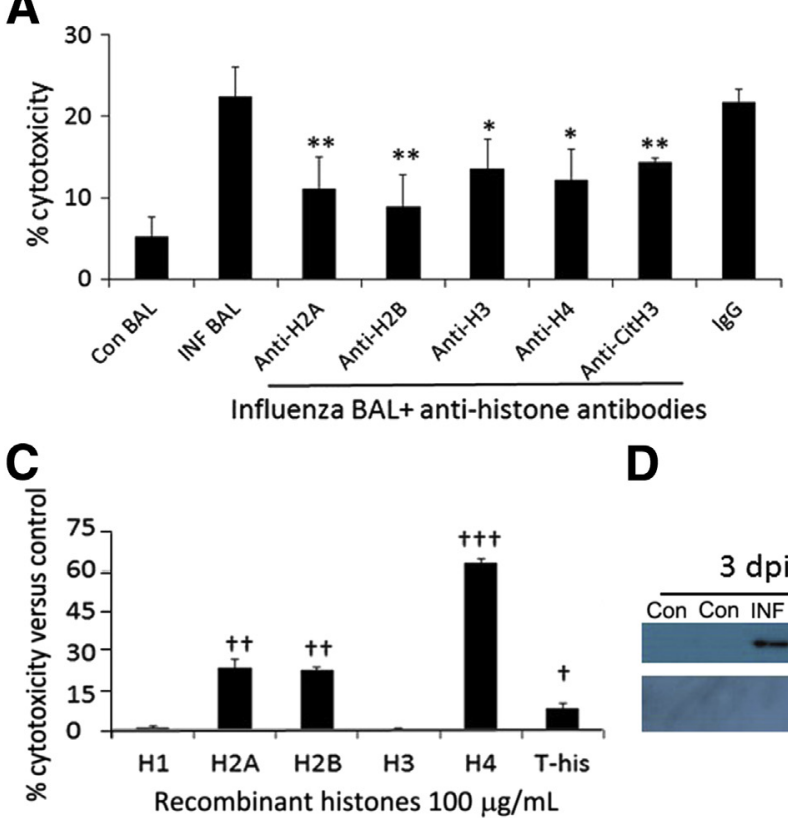

B

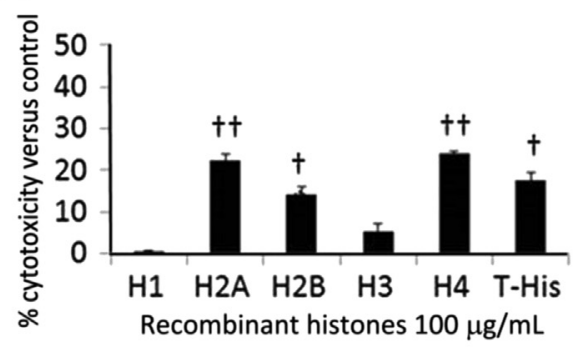

E

Figure 3 Cytotoxicity of histones. A: Bronchoalveolar lavage (BAL) fluids from control (Con) and influenza-infected (INF) mice were tested for their cytotoxic effects in $\mathrm{A} 549$ cells by a lactate dehydrogenase (LDH) release assay. BAL fluids were preincubated with antibodies against H2A, H2B, H3, H4, citrullinated (cit) H3, or control IgG $(10 \mu \mathrm{g} / \mathrm{mL})$ with A549 cells, and LDH release was measured after 16 hours. The infected BAL show a fourfold increase over the control BAL, and antihistone antibodies are associated with significant blocking of cytotoxic responses. B and C: Cytotoxic effects of individual histones. Recombinant histones $\mathrm{H1}, \mathrm{H} 2 \mathrm{~A}, \mathrm{H} 2 \mathrm{~B}, \mathrm{H} 3, \mathrm{H} 4$ and total histones $(5 \mu \mathrm{g} / \mathrm{mL})$ were tested for their cytotoxicity in A549 (B) and endothelial (C) cells. H4, H2B, and $\mathrm{H} 2 \mathrm{~A}$ reveal higher cytotoxicity than other histones. D: Western blot analysis of T1 $\alpha$ and thrombomodulin levels, which are indicative of epithelial and endothelial damage, respectively, in BAL fluid collected from mock- and influenza-infected mice. E: Protein leakage measured by total protein content in BAL supernatants from control and infected mice. Data are expressed as means \pm SEM. $n=4$ (A and E); $n=5$ (B-D). ${ }^{*} P<0.05$ and ${ }^{* *} P<0.01$ versus INF; ${ }^{\dagger} P<0.05,{ }^{\dagger \dagger} P<0.01$, and ${ }^{\dagger \dagger} P<0.001$ versus control.

The histones were mainly lodged in areas with disrupted alveolar-capillary surfaces and pulmonary vasculature, consistent with a role in tissue injury.

\section{Influenza Infection Increases Levels of Extracellular Histones in Humans}

Nasal wash and plasma samples collected from influenza $\mathrm{A}-$ or influenza $\mathrm{B}-$ positive and influenza-negative patients were analyzed. Interestingly, extracellular histone levels were significantly higher in nasal wash samples collected from influenza $\mathrm{A}$-positive patients than were those from influenza B-positive or influenza-negative patients (Figure 2C). Extracellular histone levels were significantly higher in influenza B-positive samples than in negative plasma samples (Figure 2E). These results demonstrate the accumulation of extracellular histones during influenza infection in humans.

\section{Extracellular Histones Released during Influenza Infection Induce Cytotoxicity in Vitro}

To assess the pathogenic role of histones released during influenza pneumonia, cell-free BAL supernatants from influenza-infected or mock-infected mice were added to lung epithelial (A549) cells. Influenza-infected BAL supernatants were associated with high cytotoxicity in A549 cells, which was significantly reduced with antihistone antibodies (Figure 3A). Among different antibodies, blocking with anti-H2A, anti-H2B, and anti-H4 antibodies was associated with relatively greater inhibition of cytotoxicity compared with blocking with the other histone antibodies.

Among different histone types, recombinant H2A, H2B, and $\mathrm{H} 4$ were associated with greater cytotoxicity in both epithelial and endothelial cells than were the other histones (Figure 3, B and C). Compared with other histones, histones $\mathrm{H} 4, \mathrm{H} 2 \mathrm{~B}$, and $\mathrm{H} 3$ were associated with the promotion of high platelet aggregation, ${ }^{23}$ suggesting that the cytotoxic effects of histones vary. Cytotoxicity was dependent on the concentration of histones (unpublished data). These findings were further supported by increased $\mathrm{T} 1 \alpha$ and thrombomodulin levels in BAL, which are indicative of epithelial and endothelial damage, respectively (Figure 3D), and ultimately lead to vascular leakage, as evidenced by increased protein levels in the BAL supernatants (Figure 3E).

In support of the extracellular histones cytotoxicity in mice, we also found that nasal wash samples from influenza A-infected patients triggered cytotoxicity in alveolar epithelial cells (Supplemental Figure S2B). Furthermore, to determine whether neutrophils contribute to the accumulated histones in nasal wash samples, MPO assay was performed. MPO activities were significantly high in influenza 
A

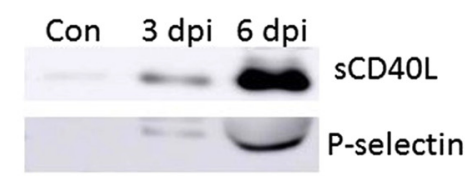

D

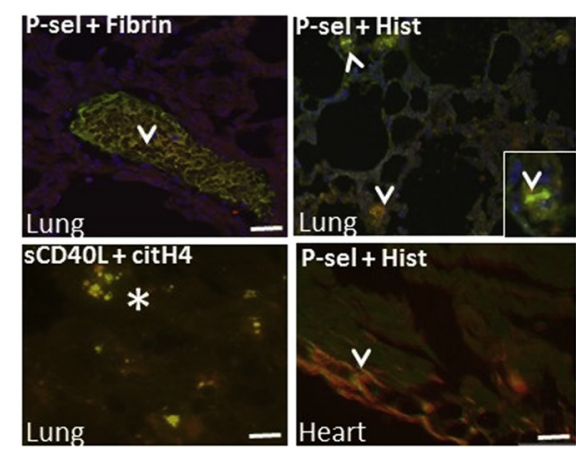

B

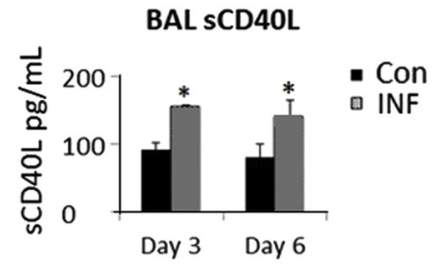

E

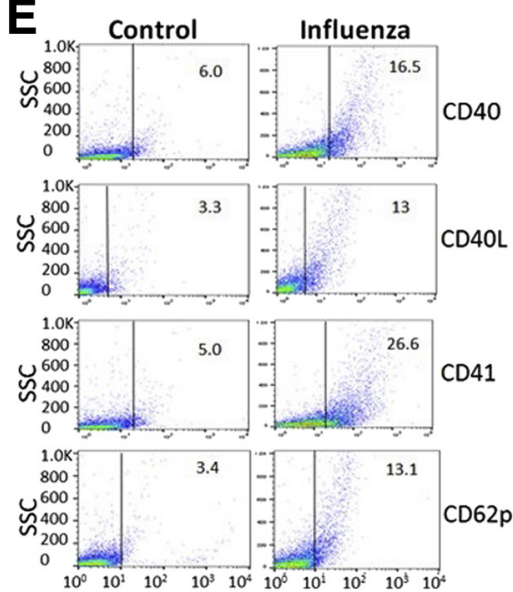

C $\quad$ SCD40L from platelets

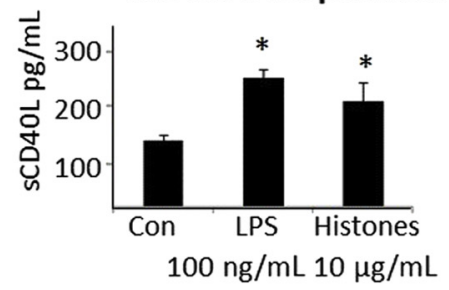

$\mathbf{F}$

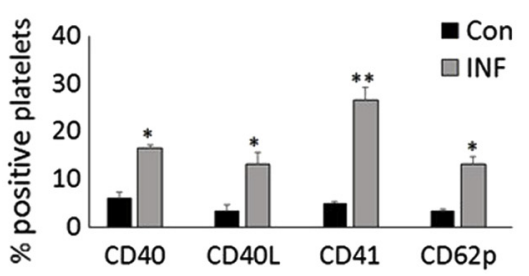

Figure 4 Prothrombotic effects during influenza and association of histones with platelets and fibrin in microvascular thrombi. A: Influenza infection enhances soluble CD40 ligand (sCD40L) release and P-selectin (marker of platelet activation) in the lungs, as evaluated in bronchoalveolar lavage (BAL) fluids by Western blot analysis. B: SCD40L in BAL fluids as assessed by enzyme-linked immunosorbent assay. C: Stimulation of platelets with histones also enhances the sCD40L release. D: Double immunostaining of lung and heart sections from mock or influenza-infected mice was performed. Immunostaining for P-selectin (P-sel), fibrin, and citrullinated (cit) H3 (Hist) shows that neutrophil extracellular trap (NET) release and histones are associated with platelets and fibrin in the thrombi in lungs (arrowheads). Inset shows co-localization of p-selectin with citH3 (arrowhead). Similarly, staining of sCD40L also shows co-localization with citH4 in the lungs (asterisk). E: Flow cytometry analysis of platelets isolated from control (mock-infected; Con) mice or influenza-infected (2500 tissue culture infectivity dose) mice at 3 days postinfection (dpi). Platelets were labeled with anti-CD40 PerCP-Cy5.5 or anti-CD41 phycoerythrin or anti-CD40 ligand fluorescein isothiocyanate or anti-CD62p (P-selectin) APC. F: Expression of different cell surface markers of platelets in both control and influenza-infected mice. Data are expressed as means \pm SEM. $n=3$ to $4(\mathbf{E}) ; n=4$ to $5(\mathbf{A}, \mathbf{B}$, and $\mathbf{D}) .{ }^{*} P<0.05$ and ${ }^{*} P<0.01$ versus control. Scale bars $=20 \mu \mathrm{m}$. SSC, side scatter.

A-infected patient samples compared with influenzanegative patient samples (Supplemental Figure S2A).

\section{Histone-Associated Prothrombotic Effects during Influenza Pneumonia}

Extracellular histones have been linked to platelet aggregation and thrombosis. ${ }^{23,45}$ Widespread pulmonary MT was observed in lethal influenza-infected mice. The association of histones with MT was evidenced by strong colocalization of histones with platelets and fibrin in the pulmonary vasculature and in the heart in influenza-infected mice (Figure 4D). Similarly, increased plasma fibrinogen degradation product levels (control, $1.2 \pm 0.3 \mu \mathrm{g} / \mathrm{mL}$; infected, $2.22 \pm 0.2 \mu \mathrm{g} / \mathrm{mL}$ ) indicated a prothrombotic status during influenza pneumonia. Among various inflammatory mediators that contribute to the development of thrombosis, $\mathrm{sCD} 40 \mathrm{~L}$ has been shown as a strong inducer of platelet aggregation. ${ }^{27}$ An increase in lung sCD40L levels was observed after influenza viral infection, as evaluated by Western blot analysis and ELISA (Figure 4, A and B). Increased expression of cell-bound $\mathrm{CD} 40 \mathrm{~L}$ and its receptor
CD40 was also found in platelets isolated from influenzainfected mouse lungs, as analyzed by flow cytometry (Figure 4, E and F). Furthermore, to determine whether histones trigger $\mathrm{sCD} 40 \mathrm{~L}$ from platelets, isolated mouse platelets were incubated with histones. Histones were associated with a significant increase in $\mathrm{SCD} 40 \mathrm{~L}$ in platelets (Figure 4C); in support of this finding, a strong colocalization of histones was found with SCD40L within microvascular thrombi, as analyzed by immunostaining (Figure 4D). Interestingly, lung-recruited platelets during influenza also showed high induction of CD62p and CD41, which support the increased platelet aggregation and MT observed on histopathologic analysis (Figure 4, E and F).

\section{Histones Do Not Show Antiviral Effects, but Exacerbate Lung Pathology}

The bactericidal effects of histones are well characterized. ${ }^{22}$ A recent study demonstrated that histones inhibit viral growth in vitro. ${ }^{41}$ To assess the antiviral effects of histones, mice were challenged with sub-lethal influenza infection. Histones were pre-incubated with the virus before 


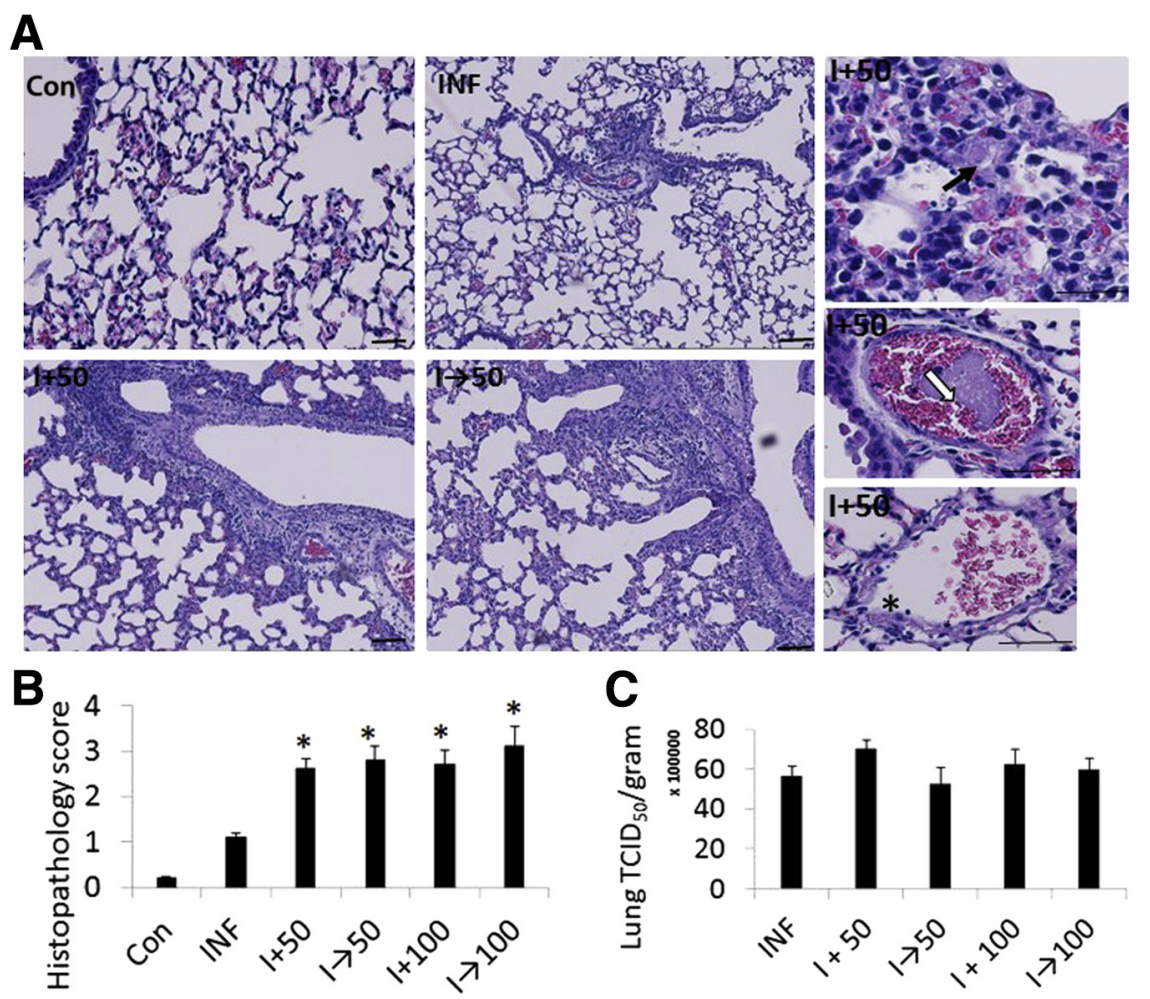

Figure 5 Histone treatment does not protect against influenza. A: Histopathology analysis shows an increase in pathologic lesions and microvascular thrombosis in mice treated with histones. Control (Con) mouse lung shows normal lung architecture. Sublethal influenza-infected (INF) mouse lungs show mild bronchiolitis and occasional alveolar damage. Mice treated with histones (50 $\mu \mathrm{g} /$ mouse) combined with virus $(\mathrm{I}+50)$ or administered 12 hours after viral infection $(I \rightarrow 50)$ show extensive bronchiolitis and alveolitis. Prominent platelet aggregation in pulmonary microvasculature (black arrow) or small blood vessels (white arrow) and endothelial necrosis (asterisk) are observed in histone-treated mice. B: Histopathology scores show a significant increase in both the 50 - and $100-\mu \mathrm{g}$ histone treatment groups. C: Virus levels. No significant differences in lung virus levels are observed. Data are expressed as means \pm SEM. $n=3$ per group $(\mathbf{A}-\mathbf{C}) .{ }^{*} P<0.05$ versus INF. Scale bars $=40 \mu \mathrm{m}$. I +50 or I +100 , virus pre-incubated with histones; $\mathrm{I} \rightarrow 50$ or $\mathrm{I} \rightarrow 100$, viral infection followed by histone treatment after 12 hours; $\mathrm{TCID}_{50}$, tissue culture infectivity dose. inoculation into mice, or were administered at 12 hours after influenza infection by intranasal delivery in sub-lethal influenza-challenged mice. Mice challenged with influenza alone showed mild bronchiolitis and focal alveolar damage with inflammation. Animals infected with the virus combined with histones or those that were administered histones at 12 hours after infection showed widespread alveolar damage, fibrin deposition, high inflammation, severe bronchiolitis, and pulmonary edema (Figure 5A). Treatment with histones at both concentrations showed no difference in lung histopathology scores (Figure 5B). The addition of histones was associated with significant increases in MT and endothelial necrosis (Figure 5A). Animals infected with sub-lethal influenza alone did not show prominent vascular thrombosis. Furthermore, no differences were found in lung virus levels in the presence of histones (Figure 5C).

Next, to confirm the role of histones in cytotoxicity and microvascular thrombi in the lungs, purified histones were inoculated into naive mice. The intranasal inoculation of purified histones was associated with extensive bronchiolar and alveolar epithelial necrosis and prominent MT (Figure 6, $\mathrm{A}-\mathrm{C}$ ). The airway epithelium showed vacuolization and disintegrated nuclei that appeared to slough from the basement, the most common pathologic lesion observed in severe influenza (Figure 6B). Histones were also detected in microvascular thrombi (Figure 6D). TUNEL staining showed significant increases in apoptosis in both the alveolar and airway epithelium in histone-administered mouse lungs but not in control lungs, thus supporting histone cytotoxicity (Figure 6, E and F). Mice inoculated with $50 \mu \mathrm{g}$ of histones also showed mild lung damage (H.K.A. and N.T., unpublished data).

\section{Histones Induce NET Release from Neutrophils in Vitro}

The stimulation of neutrophils with low concentrations of histones produced NETs (Figure $6 \mathrm{H}$ ). However, $10 \mu \mathrm{g} / \mathrm{mL}$ histones showed cytotoxicity in neutrophils, which resulted in necrotic death (data not shown). The induction of NET histones was significantly diminished in the presence of antihistone antibodies (Figure 6I). Neutrophils isolated from influenza-infected mouse lungs showed attachment of histones on the surface of the neutrophil membranes (Figure 6G). These findings indicate a cycle of events that can be triggered by initial NET release during influenza, which eventually may contribute to lung pathology.

\section{Monoclonal Antihistone Antibodies Alleviate Lung Pathology and Show Additive Effects when Combined with Oseltamivir}

The effects of antihistone antibodies, alone or in combination with oseltamivir, on lung pathology were evaluated. Oseltamivir $20 \mathrm{mg} / \mathrm{kg}$, which is equivalent to the recommended dose in humans, was used. ${ }^{46}$ Histopathologic analysis at 8 dpi revealed that the administration of antihistone antibodies alone or in combination with oseltamivir was associated with significantly reduced alveolar-capillary 

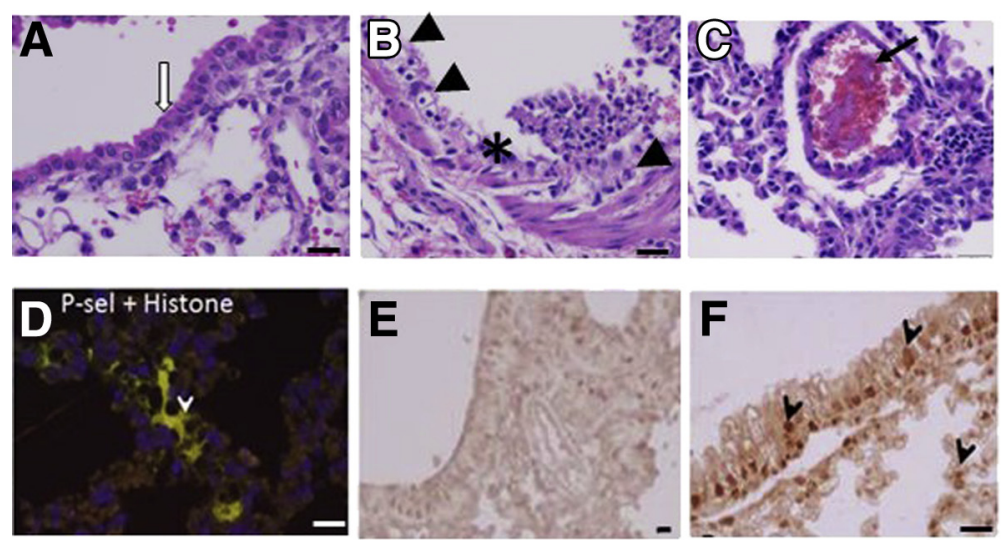

G
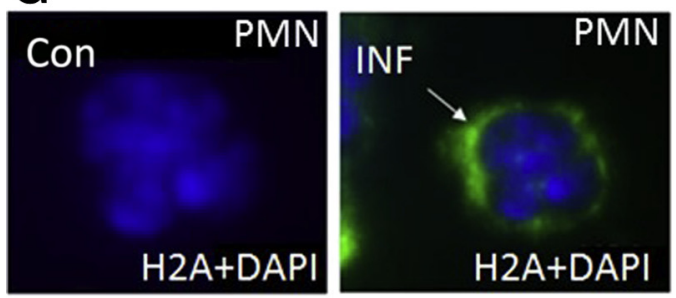

H
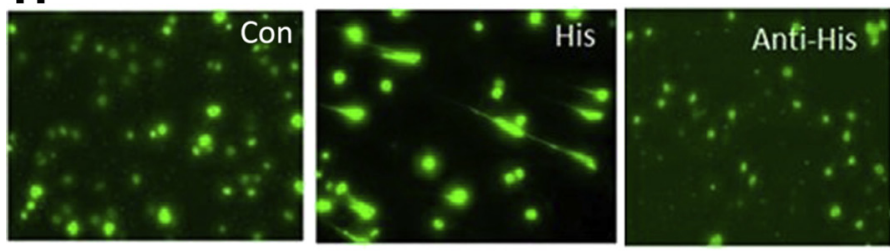

Figure 6 Effect of purified histones in vivo and in vitro. Purified histones $(100 \mu \mathrm{g})$ were intranasally inoculated into mice. A: Histopathology analyses show normal epithelium in phosphatebuffered saline-inoculated control mouse lungs (arrow). B: Histone inoculation disrupts the airway epithelium, with vacuolization and loss of cytoplasm of epithelium (arrowheads) and in some areas it shows denudation of epithelium (asterisk). C: Microvascular thrombosis (arrow). D: Double immunostaining shows co-localization of histones with platelets (arrowhead). E: Control mouse lungs show no TUNEL-positive cells. F: TUNEL assay shows extensive bronchiolar epithelial and alveolar epithelial damage after histone inoculation into mice (arrowheads). G: Neutrophils (PMN) isolated from influenza-infected mice (INF) show interaction of histones on to the neutrophil cell membranes (arrow), whereas neutrophils from mock-infected mice [control (Con)] do not show histone staining. H: Neutrophils isolated from influenza-infected mice incubated with histones (His; $5 \mu \mathrm{g} / \mathrm{mL}$ ) or phorbol 12-myristate 13-acetate (PMA; $100 \mathrm{ng} / \mathrm{mL}$ ) for 2 hours. Neutrophil extracellular trap (NET) induction was visualized using Sytox Green staining. I: Stimulation with histones significantly induces NETs, which are abrogated by antihistone antibodies (antiHis $\mathrm{Ab} ; 10 \mu \mathrm{g} / \mathrm{mL}$ ). Data were obtained from three independent experiments. Data are expressed as means \pm SEM. ${ }^{\star} P<0.05$ versus control; ${ }^{\dagger} P<0.05$ versus histone. Scale bars $=40 \mu \mathrm{m}(\mathbf{A}-\mathbf{F})$. Original magnification: $\times 100(\mathbf{G}) ; \times 20(\mathbf{H})$. damage and MT in lethal influenza-infected mice (Figure 7, A and B). Interestingly, mice treated with both antihistone antibodies and oseltamivir showed $40 \%$ protection (Figure 7C). All mice in the infected-alone and antihistone antibody-alone groups were euthanized as they showed severe clinical signs (H.K.A. and N.T., unpublished data). Animals treated with histone antibodies alone did not show any pathologic lesions in the lungs and other organs. Currently we are investigating the effects of Fab fragments of antihistone monoclonal antibodies, and testing i.v. and intranasal delivery together with antiviral agents.

\section{Discussion}

This study revealed that accumulated extracellular histones during influenza infection in mice contribute to alveolarcapillary damage and pulmonary MT that ultimately lead to vascular leakage, pulmonary hemorrhage, and respiratory failure. Increased levels of extracellular histones were also found in nasal wash and plasma samples from influenzainfected patients, indicating a possible clinical relevance of elevated histones in pulmonary injury. Furthermore, the administration of antihistone antibodies in combination with the antiviral agent oseltamivir reduced lung pathology and improved survival in mice challenged with lethal influenza virus. These findings provide a novel basis for the role of extracellular histones in lung pathogenesis during influenza.

Our previous studies have demonstrated that excessive neutrophil influx and their released NETs contribute to acute lung injury during influenza pneumonia as well as during pneumococcal superinfection after influenza. ${ }^{7,12}$ Histones are major protein components in NETs and are essential in nuclear organization in intact cells. However, when released into the extracellular environment, histones are highly cytotoxic, induce thrombosis, and contribute to tissue damage. ${ }^{17,18,47}$ We demonstrated that influenza infection induced severe lung pathology together with excessive accumulations of extracellular histones. Histone accumulation was predominant in the areas of the lungs showing tissue consolidation and disintegrated alveolar architecture.

These findings suggest a putative role of extracellular histones in causing lung damage through inflicting epithelial and endothelial damage. Histones are known to effect cytotoxic changes by disrupting cell membranes through binding to phospholipids and increasing calcium influx. ${ }^{18}$ These changes lead to the disintegration of subcellular components, which eventually leads to cell death. ${ }^{17}$ Based on in vitro lactate dehydrogenase release assays, a significant increase in cytotoxicity was found when epithelial cells were incubated with cell-free BAL fluid 
A
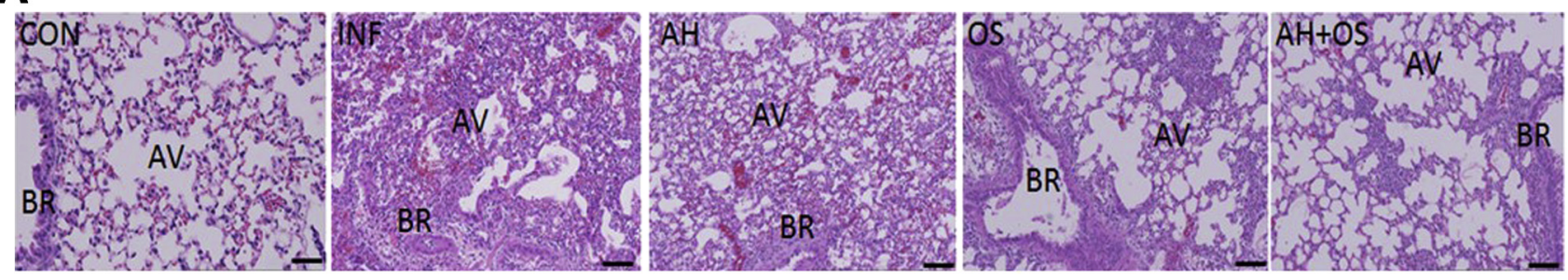

B

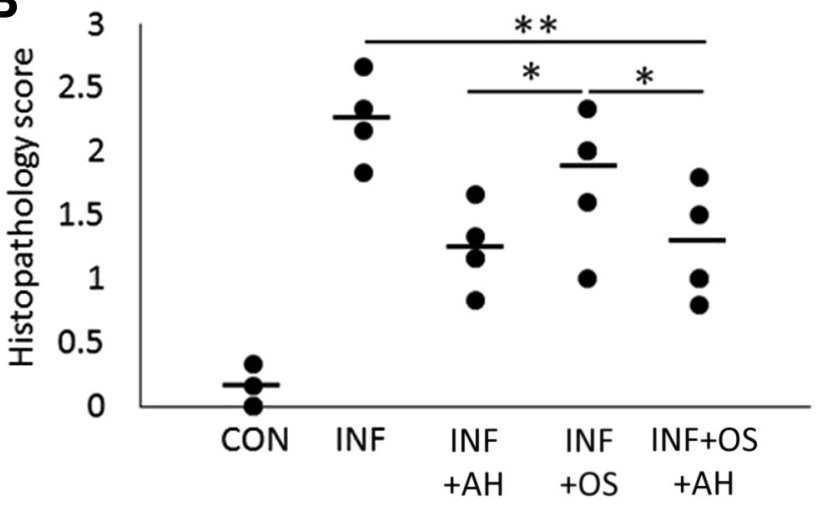

C

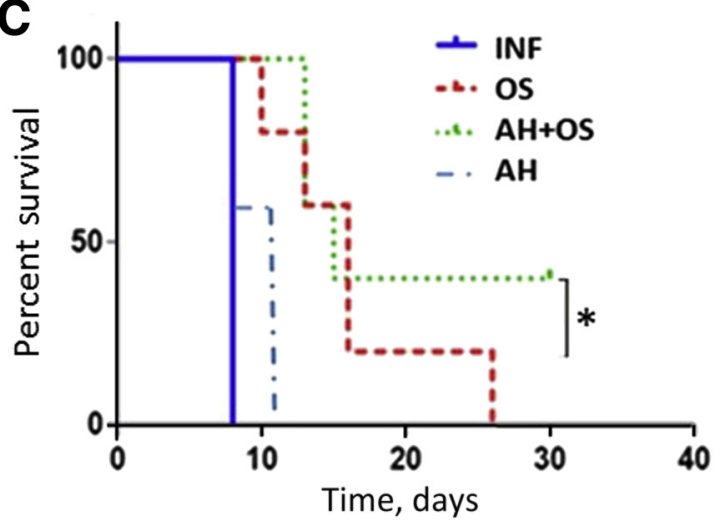

Figure 7 Effects of antihistone $(\mathrm{AH})$ antibody treatment alone or in combination with oseltamivir (OS) on lung pathology and survival. A: The AH and $\mathrm{AH}+\mathrm{OS}$ groups show less alveolar damage and necrotic bronchiolitis than do the infected (INF) or OS groups. Control (CON; mock-infected) mice do not show any pathologic lesions. B: Semiquantitative analysis of histopathology scores shows a significant reduction in lung pathology scores in the $\mathrm{AH}$ and $\mathrm{AH}+\mathrm{OS}$ animal groups compared with the other groups. C: The combination of antihistone antibodies and oseltamivir (AH+OS) is associated with significantly reduced severe lung pneumonia and improved survival compared with those in the other groups. $n=10$ mice per group ( 5 for histopathology and 5 for survival studies). ${ }^{*} P<0.05,{ }^{*} P<0.01$. Scale bars $=40 \mu \mathrm{m}$. AV, alveoli; BR, bronchiole.

samples collected from influenza-infected mice and compared with cell-free BAL fluid samples from mock-infected mice. In addition, antibody-blocking analysis revealed that histones $\mathrm{H} 4$, $\mathrm{H} 2 \mathrm{~A}$, and $\mathrm{H} 2 \mathrm{~B}$ produced higher cytotoxic responses than did other histone types. ${ }^{17}$ Increases in MPO activity and cytotoxic response by influenza-infected human nasal wash samples support the involvement of neutrophils in tissue injury during influenza. Consistent with these results, recombinant individual histones H4, H2A, and H2B were found to induce more cytotoxicity in alveolar epithelial and endothelial cells compared with $\mathrm{H} 4$ and $\mathrm{H} 1$. This finding highlights the variability in cytotoxic potential among different histone types. Virusinflicted cytopathic effects showing widespread epithelial necrosis and denudation are commonly observed during severe influenza infection in humans and also in mice experimentally infected with influenza virus. ${ }^{24,39,42}$ To examine the role of histones in these pathologic events, purified histones were intranasally infused in mice, resulting in denudation of the airway epithelial lining, with extensive vacuolization and loss of cytoplasm, and increased apoptosis. These findings clearly demonstrate a potential pathogenic role of histones in inflicting epithelial and endothelial damage during influenza pneumonia.

Aberrant coagulation effects with high platelet aggregation, pulmonary vascular thrombosis, and endothelial injury have been linked to lung pathogenesis in severe influenza pneumonia. ${ }^{24-26}$ Pulmonary capillary thrombosis during influenza was first described in autopsy analyses of lungs from victims of the 1918 Spanish flu outbreak. ${ }^{44}$ Augmented pulmonary thrombosis and fibrin thrombi were also observed in patients fatally infected with the 2009 pandemic swine influenza virus. ${ }^{3,48}$ Similar to these clinical findings, our studies revealed widespread pulmonary MT in influenza-infected mouse lungs. Small blood vessels occluded with fibrin-rich platelet aggregates are frequently surrounded by hemorrhagic effusions and edema fluids due to ischemia and rupture of blood vessels. Our findings showing a strong co-localization of extracellular histones with platelets and fibrin during influenza support its possible role in the development of MT. Furthermore, intranasal infusion of purified histones was found to induce MT and endothelial necrosis in normal mice. These findings were in agreement with those from a previous report that i.v. infusion of histones induced fibrin- and platelet-rich pulmonary microvascular thrombi in a mouse model of sepsis. ${ }^{17}$ To understand the possible interaction of histones with platelets in the development of thrombosis during influenza, levels of sCD40L, a strong inducer of platelet aggregation, were evaluated in the lungs. ${ }^{49}$ Influenza infection induces a significant increase in SCD40L release in the lungs. Similarly, platelets collected from influenza-infected mouse lungs showed enhanced surface expression of CD40L and its receptor CD40, indicating activation of CD40-CD40L signaling during influenza. Furthermore, significant induction of CD41 expression was found in lung-recruited 
platelets after influenza infection. CD41 is a fibrinogen receptor, involved in platelet aggregation. These findings underline our pathologic analysis demonstrating high platelet aggregation and pulmonary MT, especially in the damaged capillaries and small blood vessels in influenzainfected mice. The induction of cell bound CD62p expression has been shown to interact with neutrophil P-selectin glycoprotein ligand-1 and helps in the recruitment of neutrophils. ${ }^{50}$ Co-localization of histones with sCD40L in infected lungs and release of sCD40L from mouse platelets after stimulation with histones suggest a possible role of histones in platelet activation and aggregation during influenza. The mechanisms of interaction of histoneplatelets and their involvement in platelet aggregation warrants further investigation.

Extracellular histone proteins have been well characterized for their bactericidal effects. ${ }^{22}$ A recent study demonstrated that histones inhibit influenza virus replication in vitro and thus may have therapeutic effects against influenza infection. ${ }^{41}$ To examine whether histones have a protective role against influenza pathogenesis, histones were exogenously infused into mice infected with sub-lethal influenza virus. Histones pre-incubated with the virus or administered at 12 hours after infection did not decrease viral loads. Instead, augmented alveolitis and pulmonary vascular thrombosis were found after histone administration, further supporting a potential role for histones in pulmonary injury. The in vitro antiviral effects of histones may not translate in vivo due to their direct cytotoxic and coagulatory effects that may exacerbate lung-pathology epithelial and endothelial effects. Furthermore, the histone-induced NETs released from these damaged cells can exacerbate acute lung injury through the presence of additional extracellular histones.

Accumulated evidence strongly supports that contributors to lung damage in influenza include uncontrolled viral growth as well as host-induced tissue injury. In a clinical study in patients positive for H1N1 pneumonia and complications of ARDS, treatment with oseltamivir and methylprednisolone (a synthetic glucocorticoid) showed significant improvement. ${ }^{51}$ Treatment with doxycycline (an inhibitor of matrix metalloproteinases) reduced lung injury, but failed to protect from lethal influenza infection. ${ }^{34} \mathrm{~A}$ combination treatment with a recombinant hepatocyte growth factor (a mitogen for alveolar type II epithelium) and oseltamivir decreased mortality in mice. ${ }^{38}$ Our current findings show a reduction in lung injury after the administration of antihistone antibodies. Pathologic lesions of alveolitis, inflammation, and MT were reduced. Although lung injury was reduced in animals treated with antihistone antibodies, the animals ultimately succumbed to infection and exhibited virus-inflicted lung pathology. A combination of antihistone antibodies together with oseltamivir at dose levels recommended in humans showed significant protection of mice against lethal influenza infection. In conclusion, our studies demonstrate that extracellular histones released during influenza exacerbate tissue injury by disrupting the alveola-capillary barrier. Histones also induce platelet aggregation, which results in widespread MT, pulmonary hemorrhage, and endothelial necrosis. Concurrent treatment of influenza-infected mice with antihistone antibodies and antiviral drugs reduced tissue damage and downstream pathologies and may provide a better therapeutic option for the treatment of influenza pneumonia.

\section{Acknowledgments}

H.K.A., N.C.M., J.M.R., R.R., V.T.K.C., and N.T. designed experiments; H.K.A., N.C.M., J.M.R., M.A., M.P., S.P., and N.T. acquired and analyzed data; T.A.S. performed histopathology and pathology analyses; P.G.T. collected human samples; C.T.E. developed monoclonal antibodies; J.R.M., J.W.R., R.R., and V.T.K.C wrote and reviewed the manuscript.

\section{Supplemental Data}

Supplemental material for this article can be found at https://doi.org/10.1016/j.ajpath.2017.09.014.

\section{References}

1. Short KR, Kroeze EJ, Fouchier RA, Kuiken T: Pathogenesis of influenza-induced acute respiratory distress syndrome. Lancet Infect Dis 2014, 14:57-69

2. Kumar A, Zarychanski R, Pinto R, Cook DJ, Marshall J, Lacroix J, Stelfox T, Bagshaw S, Choong K, Lamontagne F, Turgeon AF, Lapinsky S, Ahern SP, Smith O, Siddiqui F, Jouvet P, Khwaja K, McIntyre L, Menon K, Hutchison J, Hornstein D, Joffe A, Lauzier F, Singh J, Karachi T, Wiebe K, Olafson K, Ramsey C, Sharma S, Dodek P, Meade M, Hall R, Fowler RA; Canadian Critical Care Trials Group H1N1 Collaborative: Critically ill patients with 2009 influenza A (H1N1) infection in Canada. JAMA 2009, 302: 1872-1879

3. Harms PW, Schmidt LA, Smith LB, Newton DW, Pletneva MA, Walters LL, Tomlins SA, Fisher-Hubbard A, Napolitano LM, Park PK, Blaivas M, Fantone J, Myers JL, Jentzen JM: Autopsy findings in eight patients with fatal H1N1 influenza. Am J Clin Pathol 2010, 134:27-35

4. Wang H, Xiao X, Lu J, Chen Z, Li K, Liu H, Luo L, Wang M, Yang Z: Factors associated with clinical outcome in 25 patients with avian influenza A (H7N9) infection in Guangzhou, China. BMC Infect Dis 2016, 16:534

5. Nie Q, Zhang DY, Wu WJ, Huang CL, Ni ZY: Extracorporeal membrane oxygenation for avian influenza A (H7N9) patient with acute respiratory distress syndrome: a case report and short literature review. BMC Pulm Med 2017:17-38

6. Xu T, Qiao J, Zhao L, Wang G, He G, Li K, Tian Y, Gao M, Wang J, Wang H, Dong C: Acute respiratory distress syndrome induced by avian influenza A (H5N1) virus in mice. Am J Respir Crit Care Med 2006, 174:1011-1017

7. Narasaraju T, Yang E, Samy RP, Ng HH, Poh WP, Liew AA, Phoon MC, van Rooijen N, Chow VT: Excessive neutrophils and neutrophil extracellular traps contribute to acute lung injury of influenza pneumonitis. Am J Pathol 2011, 179:199-210

8. Traylor ZP, Aeffner F, Davis IC: Influenza A H1N1 induces declines in alveolar gas exchange in mice consistent with rapid post-infection 
progression from acute lung injury to ARDS. Influenza Other Respir Viruses 2013, 7:472-479

9. Cheung CY, Leung CY, Nicholls JM: Innate immune responses to influenza A H5N1: friend or foe? Trends Immunol 2009, 30:574-584

10. Kash JC, Taubenberger JK: The role of viral, host, and secondary bacterial factors in influenza pathogenesis. Am J Pathol 2015, 185: $1528-1536$

11. Ramos I, Fernandez-Sesma A: Modulating the innate immune response to influenza A virus: potential therapeutic use of antiinflammatory drugs. Front Immunol 2015, 6:361

12. Narayana Moorthy A, Narasaraju T, Rai P, Perumalsamy R, Tan KB, Wang S, Engelward B, Chow VT: In vivo and in vitro studies on the roles of neutrophil extracellular traps during secondary pneumococcal pneumonia after primary pulmonary influenza infection. Front Immunol 2013, 4:56

13. Moorthy AN, Rai P, Jiao H, Wang S, Tan KB, Qin L, Watanabe H, Zhang Y, Teluguakula N, Chow VT: Capsules of virulent pneumococcal serotypes enhance formation of neutrophil extracellular traps during in vivo pathogenesis of pneumonia. Oncotarget 2016, 7:19327-19340

14. Narasaraju T, Harshini A: Neutrophils as possible therapeutic targets in severe influenza pneumonia. J Infect Pulm Dis 2016, 2:doi:10. 16966/2470-3176.115

15. Ivan FX, Rajapakse JC, Welsch RE, Rozen SG, Narasaraju T, Xiong GM, Engelward BP, Chow VT: Differential pulmonary transcriptomic profiles in murine lungs infected with low and highly virulent influenza H3N2 viruses reveal dysregulation of TREM1 signaling, cytokines, and chemokines. Funct Integr Genomics 2012, 12:105-117

16. Audrey-Ann L, Narasaraju T, Tan KB, Wang S, Phoon MC, Chow VT: Caspase-1-deficient mice are more susceptible to influenza pneumonitis. Eur J Inflamm 2014, 12:117-130

17. Xu J, Zhang X, Pelayo R, Monestier M, Ammollo CT, Semeraro F, Taylor FB, Esmon NL, Lupu F, Esmon CT: Extracellular histones are major mediators of death in sepsis. Nat Med 2009, 15:1318-1321

18. Abrams ST, Zhang N, Manson J, Liu T, Dart C, Baluwa F, Wang SS, Brohi K, Kipar A, Yu W, Wang G, Toh CH: Circulating histones are mediators of trauma-associated lung injury. Am J Respir Crit Care Med 2013, 187:160-169

19. Allam R, Scherbaum CR, Darisipudi MN, Mulay SR, Hägele H, Lichtnekert J, Hagemann JH, Rupanagudi KV, Ryu M, Schwarzenberger C, Hohenstein B, Hugo C, Uhl B, Reichel CA, Krombach F, Monestier M, Liapis H, Moreth K, Schaefer L, Anders HJ: Histones from dying renal cells aggravate kidney injury via TLR2 and TLR4. J Am Soc Nephrol 2012, 23:1375-1388

20. Wildhagen KC, Wiewel MA, Schultz MJ, Horn J, Schrijver R, Reutelingsperger CP, van der Poll T, Nicolaes GA: Extracellular histone H3 levels are inversely correlated with antithrombin levels and platelet counts and are associated with mortality in sepsis patients. Thromb Res 2015, 136:542-547

21. Zhang Y, Wen Z, Guan L, Jiang P, Gu T, Zhao J, Lv X, Wen T: Extracellular histones play an inflammatory role in acid aspiration-induced acute respiratory distress syndrome. Anesthesiology 2015, 122:127-139

22. Lee DY, Huang CM, Nakatsuji T, Thiboutot D, Kang SA, Monestier M, Gallo RL: Histone H4 is a major component of the antimicrobial action of human sebocytes. J Invest Dermatol 2009, 129:2489-2496

23. Fuchs TA, Bhandari AA, Wagner DD: Histones induce rapid and profound thrombocytopenia in mice. Blood 2011, 118:3708-3714

24. Taubenberger JK, Morens DM: The pathology of influenza virus infections. Annu Rev Pathol 2008, 3:499-522

25. Lê VB, Schneider JG, Boergeling Y, Berri F, Ducatez M, Guerin JL, Adrian I, Errazuriz-Cerda E, Frasquilho S, Antunes L, Lina B, Bordet JC, Jandrot-Perrus M, Ludwig S, Riteau B: Platelet activation and aggregation promote lung inflammation and influenza virus pathogenesis. Am J Respir Crit Care Med 2015, 191:804-819

26. Yang Y, Tang H: Aberrant coagulation causes a hyper-inflammatory response in severe influenza pneumonia. Cell Mol Immunol 2016, 13 : $432-442$
27. Yacoub D, Hachem A, Théorêt JF, Gillis MA, Mourad W, Merhi Y: Enhanced levels of soluble CD40 ligand exacerbate platelet aggregation and thrombus formation through a CD40-dependent tumor necrosis factor receptor-associated factor-2/Rac1/p38 mitogenactivated protein kinase signaling pathway. Arterioscler Thromb Vasc Biol 2010, 30:2424-2433

28. Schönbeck U, Libby P: The CD40/CD154 receptor/ligand dyad. Cell Mol Life Sci 2001, 58:4-43

29. Andre P, Nannizzi-Alaimo L, Prasad SK, Phillips DR: Plateletderived CD40L: the switch-hitting player of cardiovascular disease. Circulation 2002, 106:896-899

30. Zarnegar B, He JQ, Oganesyan G, Hoffmann A, Baltimore D, Cheng G: Unique CD40-mediated biological program in B cell activation requires both type 1 and type 2 NF- $\kappa$ B activation pathways. Proc Natl Acad Sci U S A 2004, 101:8108-8113

31. Suzuki H, Saito R, Masuda H, Oshitani H, Sato M, Sato I: Emergence of amantadine-resistant influenza A viruses: epidemiological study. J Infect Chemother 2003, 9:195-200

32. Moscona A: Oseltamivir resistance-disabling our influenza defenses. N Engl J Med 2005, 353:2633-2636

33. Dharan NJ, Gubareva LV, Meyer JJ, Okomo-Adhiambo M, McClinton RC, Marshall SA, St George K, Epperson S, Brammer L, Klimov AI, Bresee JS, Fry AM: Infections with oseltamivir-resistant influenza A (H1N1) virus in the United States. JAMA 2009, 301: $1034-1041$

34. Ng HH, Narasaraju TA, Sim MK, Chow VT: Doxycyline treatment attenuates acute lung injury in mice infected with highly virulent influenza H3N2 virus: involvement of matrix metalloproteases. Exp Mol Pathol 2012, 92:287-295

35. Smee DF, Hurst BL, Wong MH, Bailey KW, Tarbet EB, Morrey JD, Furuta Y: Effects of the combination of favipiravir (T-705) and oseltamivir on influenza A virus infections in mice. Antimicrob Agents Chemother 2010, 54:126-133

36. Ilyushina NA, Bovin NV, Webster RG, Govorkova EA: Combination chemotherapy, a potential strategy for reducing the emergence of drug-resistant influenza A variants. Antivir Res 2006, 70:121-131

37. Sharma G, Champalal Sharma D, Hwei Fen L, Pathak M, Bethur N, Pendharkar V, Peiris M, Altmeyer R: Reduction of influenza virusinduced lung inflammation and mortality in animals treated with a phosophodisestrase-4 inhibitor and a selective serotonin reuptake inhibitor. Emerg Microbes Infect 2013, 2:e54

38. Narasaraju TA, Edwin YY, Ng HH, Audrey A, Phoon MC, Chow VT: Therapeutic effect of combining hepatocyte growth factor and oseltamivir in amelioration of influenza pneumonitis. Curr Mol Med 2014, 14:1-13

39. Narasaraju T, Ng HH, Phoon MC, Chow VT: MCP-1 antibody treatment enhances damage and impedes repair of the alveolar epithelium in influenza pneumonitis. Am J Respir Cell Mol Biol 2010, 42:732-743

40. Oshansky CM, Gartland AJ, Wong SS, Jeevan T, Wang D, Roddam PL, Caniza MA, Hertz T, Devincenzo JP, Webby RJ, Thomas PG: Mucosal immune responses predict clinical outcomes during influenza infection independently of age and viral load. Am J Respir Crit Care Med 2014, 189:449-462

41. Hoeksema M, Tripathi S, White M, Qi L, Taubenberger J, van Eijk M, Haagsman H, Hartshorn KL: Arginine-rich histones have strong antiviral activity for influenza A viruses. Innate Immun 2015, $21: 736-745$

42. Mauad T, Hajjar LA, Callegari GD, da Silva LF, Schout D, Galas FR, Alves VA, Malheiros DM, Auler JO Jr, Ferreira AF, Borsato MR, Bezerra SM, Gutierrez PS, Caldini ET, Pasqualucci CA, Dolhnikoff M, Saldiva PH: Lung pathology in fatal novel human influenza A (H1N1) infection. Am J Respir Crit Care Med 2010, 181: $72-79$

43. Shieh WJ, Blau DM, Denison AM, Deleon-Carnes M, Adem P, Bhatnagar J, Sumner J, Liu L, Patel M, Batten B, Greer P, Jones T, Smith C, Bartlett J, Montague J, White E, Rollin D, Gao R, Seales C, 
Jost H, Metcalfe M, Goldsmith CS, Humphrey C, Schmitz A, Drew C, Paddock C, Uyeki TM, Zaki SR: 2009 pandemic influenza A (H1N1): pathology and pathogenesis of 100 fatal cases in the United States. Am J Pathol 2010, 177:166-175

44. LeCount ER: Disseminated necrosis o the pulmonary capillaries in influenzal pneumonia. J Am Med Assoc 1919, 72:1519-1520

45. Fuchs TA, Brill A, Wagner DD: Neutrophil extracellular trap (NET) impact on deep vein thrombosis. Arterioscler Thromb Vasc Biol 2012, 32:1777-1783

46. Nguyen JT, Smee DF, Barnard DL, Julander JG, Gross M, de Jong MD, Went GT: Efficacy of combined therapy with amantadine, oseltamivir, and ribavirin in vivo against susceptible and amantadineresistant influenza A viruses. PLoS One 2012, 7:e31006

47. Xu J, Zhang X, Monestier M, Esmon NL, Esmon CT: Extracellular histones are mediators of death through TLR2 and TLR4 in mouse fatal liver injury. J Immunol 2011, 187:2626-2631
48. Estenssoro E, Ríos FG, Apezteguía C, Reina R, Neira J, Ceraso DH, Orlandi C, Valentini R, Tiribelli N, Brizuela M, Balasini C, Mare S, Domeniconi G, Ilutovich S, Gomez A, Giuliani J, Barrios C, Valdez P: Pandemic 2009 influenza A(H1N1) in Argentina: a study of 337 patients on mechanical ventilation. Am J Respir Crit Care Med 2010, 182:41-48

49. Anand SX, Viles-Gonzalez JF, Badimon JJ, Cavusoglu E, Marmur JD: Membrane-associated CD40L and SCD40L in atherothrombotic disease. Thromb Haemost 2003, 90:377-384

50. Li J, Kim K, Hahm E, Molokie R, Hay N, Gordeuk VR, Du X, Cho J: Neutrophil AKT2 regulates heterotypic cell-cell interactions during vascular inflammation. J Clin Invest 2014, 124:1483-1496

51. Yokoyama T, Tsushima K, Ushiki A, Kobayashi N, Urushihata K, Koizumi T, Kubo K: Acute lung injury with alveolar hemorrhage due to a novel swine-origin influenza A (H1N1) virus. Intern Med 2010, $49: 427-430$ 